Elsevier

\title{
Neuroprotective effects of MK-801, TCP, PCP and CPP against $N$-methyl-D-aspartate induced neurotoxicity in an in vivo perinatal rat model
}

\author{
John W. McDonald ${ }^{1}$, Faye S. Silverstein ${ }^{2,3}$ and Michael V. Johnston ${ }^{1-4}$ \\ ${ }^{\prime}$ Neuroscience and Medical Scientist Training Program and Departments of ${ }^{2}$ Pediatrics, ${ }^{3}$ Neurology and ${ }^{4}$ Center for Human \\ Growth and Development, University of Michigan, Ann Arbor, MI (U.S.A.)
}

(Accepted 22 November 1988)

Key words: Neurotoxicity; Perinatal; MK-801; N-Methyl-D-aspartate; Hypoxia-ischemia; Neuroprotection

\begin{abstract}
Three non-competitive antagonists (MK-801, TCP, PCP) and one competitive antagonist (CPP) of $N$-methyl-D-aspartate (NMDA) receptors, were compared for their ability to antagonize neurotoxic actions of NMDA injected into the brains of 7-day-old rats. Unilateral intracerebral injection of NMDA ( $25 \mathrm{nmol} / 0.5 \mu \mathrm{l})$ into the corpus striatum of pups consistently produced severe confluent neuronal necrosis in the striatum extending into the dorsal hippocampus and overlying neocortex. The distribution of damage corresponded to the topography of NMDA type glutamate receptors in the vulnerable regions. With this lesion in developing brain, the weight of the injected hemisphere 5 days later can be used as a quantitative measure of brain injury. Intraperitoneal administration of MK-801 $(0.02-42.0 \mu \mathrm{mol} / \mathrm{kg})$, TCP $(3.5-54.0 \mu \mathrm{mol} / \mathrm{kg})$, PCP $(1.0-41.0 \mu \mathrm{mol} / \mathrm{kg})$, and $\mathrm{CPP}(1.0-60.0 \mu \mathrm{mol} / \mathrm{kg}) 15$ min after NMDA injection had prominent dose-dependent neuroprotective effects. MK-801 was 14 times more potent than other compounds tested and the $50 \%$ protective dose $\left(\mathrm{PD}_{50}\right.$, that dose which reduced damage by $50 \%$ relative to untreated NMDA-injected controls) was $0.63 \mu \mathrm{mol} / \mathrm{kg}$. Corresponding values for CPP, PCP, and TCP were $8.84,10.85$, and $24.05 \mu \mathrm{mol} / \mathrm{kg}$ respectively. The lowest dose of MK-801 that provided significant protection was $0.2 \mu \mathrm{mol} / \mathrm{kg}(0.04 \mathrm{mg} / \mathrm{kg}, 37.9 \pm 4.6 \% \mathrm{protection})$. Four $\mu \mathrm{mol} / \mathrm{kg}(0.8 \mathrm{mg} / \mathrm{kg})$ of MK-801 completely protected against NMDA-mediated damage. The study provides the first direct in vivo comparison of the neuroprotective abilities of these compounds. Systemic administrations of MK-801, TCP, PCP, and CPP all limit NMDA-induced neuronal injury in this model. The susceptibility of the immature brain to the neurotoxicity of NMDA provides a sensitive, reproducible, and quantitative in vivo system for comparing the effectiveness of drugs with protective actions against excitotoxic neuronal injury. Similarities between the neonatal NMDA model of injury and experimental hypoxic-ischemic brain damage suggest that neuroprotective activity in this system may predict activity against hypoxic-ischemic neuronal injury.
\end{abstract}

\section{INTRODUCTION}

The excitatory amino acids (EAA), glutamate and related compounds, mediate their physiological responses in brain by interacting with at least 3 receptor subtypes, named by their preferential agonists, $N$-methyl-D-aspartate (NMDA), quisqualic acid, and kainic acid. Excessive excitation of EAA receptors can result in neuronal calcium overload, neuronal injury and death ${ }^{4,39,45}$. Recent studies implicate NMDA receptor channel activation as an important mechanism in the pathogenesis of neuronal injury in hypoxia-ischemia ${ }^{34,43,44,46}$, hypoglycemia $^{52}$, sustained seizures ${ }^{8,37,47}$ and chronic neuro- degenerative diseases ${ }^{15,42}$. NMDA receptor ligands activate a calcium permeable cationic channel ${ }^{28}$ that is gated by magnesium $(\mathrm{Mg})^{32,38}$, in a voltagedependent manner ${ }^{12,29}$. Response to NMDA is enhanced by glycine ${ }^{20}$ and is non-competitively blocked in an activity-dependent manner by phencyclidine (PCP) receptor ligands including MK-801 ((+)-5-methyl-10,11-dihydro-5H-dibenzo[a,d]cyclohepten-5,10-imine maleate) and the dissociative anesthetic class of compounds ${ }^{21,31}$. There are two requirements for channel activation: (1) agonist binding to NMDA receptor and (2) sufficient membrane depolarization to relieve the $\mathrm{Mg}$ blockade. Virtually identical anatomical distributions of

Correspondence: M.V. Johnston, Kennedy Institute, 707 North Broadway, Baltimore, Maryland 21205, U.S.A. 
NMDA, PCP, and glycine receptors in the mammalian forebrain ${ }^{2.9,18,30}$ and evidence of interactions between these receptors suggest that they may be components of the same receptor-ion channel complex $^{19.41}$.

NMDA antagonists can reduce neuronal injury resulting from experimental hypoxia-ischemia ${ }^{1.14}$. ${ }^{34.46}$ hypoglycemia ${ }^{52}$ and sustained seizures ${ }^{24}$ in in vivo animal models. Development of additional potential neuroprotective compounds would be facilitated by a reproducible, cost-effective, quantitative system in which to compare neuroprotective effects of these compounds. The use of in vivo models of excitatory neuronal injury has been limited by their variability and by complexity in quantifying tissue damage.

Based on the observation that neurotoxicity of NMDA is enhanced in the immature brain compared to adult ${ }^{35}$, we developed an in vivo neonatal rodent model of NMDA-induced brain injury that provides a quantitative system for evaluating potential neuroprotective compounds ${ }^{33}$. Here we used the method to compare neuroprotective effects of MK801 directly to related non-competitive (PCP, TCP) and competitive (CPP) NMDA antagonists.

\section{MATERIALS AND METHODS}

Intracerebral injections of NMDA were performed in 7-day-old male and female SpragueDawley albino rat pups briefly but deeply anesthetized with ether, as described previously ${ }^{33}$. The calvarium was exposed by a midline incision through the skin. Pups were positioned in a plaster of Paris mold of the head and body. Intracerebral stereotaxic injections (Kopf small animal apparatus) were done using a Hamilton syringe with a 26 gauge needle. All intracerebral injections were in the posterior striatum. Coordinates were anteroposterior (AP) 2.0 $\mathrm{mm}$, mediolateral (ML) $2.5 \mathrm{~mm}$, at a depth of $4 \mathrm{~mm}$ from the dura using bregma as a landmark. The needle was left in place for two min following injections to limit leakage.

NMDA (Sigma) was dissolved in $0.01 \mathrm{M}$ Tris, $\mathrm{pH}$ 7.4. Pups received either NMDA $(25 \mathrm{nmol} / 0.5 \mu \mathrm{l})$ or vehicle $(0.5 \mu \mathrm{l})$ intrastriatally. In preliminary studies, 25 nmol NMDA produced the optimum level of damage while maintaining a low level of mortality.
Neuroprotective compounds, dissolved in phosphate-buffered saline (PBS, $\mathrm{pH} 7.4$ ), were injected intraperitoneally (i.p.) in $0.05 \mathrm{ml} 15 \mathrm{~min}$ after intracerebral injection of NMDA. Control animals received equal vols. of PBS. The timing of treatment chosen allows partial recovery from anesthesia prior to administration of the neuroprotective compound.

Three non-competitive (MK-801, TCP, PCP) and one competitive (CPP) NMDA antagonist were tested in the following dose ranges (dosages are in $\mu \mathrm{mol} / \mathrm{kg}$ and were converted from the original doses tested (in $\mathrm{mg} / \mathrm{kg}$ ) for purpose of comparison): MK-801 (0.02-41.7), TCP (3.5-54.2), PCP (1.0$41.1)$, CPP (1.0-60.0). Six to ten animals were tested at each dose. Three to four NMDA-injected, salinetreated littermate controls were included at each dose tested. Total numbers of animals used were: MK-801 $(n=48)$, TCP $(n=51)$, PCP $(n=41)$, CPP $(n=56)$, NMDA-injected saline-treated controls ( $n$ $=75$ ).

Subsequent to a 1-h recovery period following treatment, the pups were returned to the dam for 5 days. On Day 12 the animals were sacrificed by decapitation and their brains were removed and the forebrain separated from the cerebellum and brainstem. The two cerebral hemispheres were separated, weighed, and placed into $10 \%$ phosphate buffered formalin followed by a $30 \%$ sucrose/phosphatebuffered formalin solution. Representative $50 \mu \mathrm{m}$ frozen microtome coronal sections were stained for Nissl substance with Cresyl violet.

\section{Data analysis}

The hemisphere weight disparities were compared for each animal using the formula $100(C-I) / C$, a value reflecting the degree of damage ( $\%$ damage) of the injected hemisphere $(I)$ relative to the contralateral hemisphere $(C)$. The data were expressed as percent protection (mean \pm S.E.M.) for each experimental group using the formula:

$$
\begin{aligned}
& \% \text { Protection }= \\
& 100\left[1-\frac{\% \text { Damage }_{(\text {Drug treated })}}{\% \text { Damage }_{(\mathrm{NMDA}-\text { injected controls })}}\right]
\end{aligned}
$$

$\%$ Damage values for experimental groups that received an NMDA antagonist and NMDA were 
compared with control groups that received PBS and NMDA. In this model, \% damage is linear up to 30 nmol NMDA and corresponds closely with histological and neurochemical markers of neuronal injury (manuscript in preparation).

The doses that produced $50 \%$ protection (protective dose $50, \mathrm{PD}_{50}$ ) were determined by the method of Litchfield and Wilcoxon ${ }^{27}$. Statistical comparisons consisted of two-tailed independent $t$-tests and oneway analysis of variance (ANOVA). The dependent variable in all tests was \% damage except where noted otherwise. NMDA-injected controls from individual experiments were pooled for statistical comparisons, since there were no significant differences among the individual groups in the severity of injury (ANOVA).

\section{Materials}

NMDA was obtained from Sigma (St. Louis, MO). MK-801 ((+)-5-methyl-10,11-dihydro-5H-dibenzo[a,d]cyclohepten-5,10-imine maleate) was a gift from Dr. P. Anderson (Merck, Sharp and Dohme, West Point, PA). TCP (1-[1-(2-thienyl)cyclohexyl]piperidine $\mathrm{HCl})$ and $\mathrm{PCP}(1-[1-$ phenylcyclohexyl]piperidine $\mathrm{HCl}$ ) were gifts from Dr. Domino (Univ. of Mich., Ann Arbor, MI). CPP (3(( \pm )-2-carboxypiperazine-4-yl)-propyl-1-phosphonic acid) was obtained from Tocris Neuramin, Essex, U.K.).

\section{RESULTS}

Unilateral intracerebral injection of NMDA (25 $\mathrm{nmol}$ ) into 7-day-old rats resulted in prolonged tonic and tonic-clonic seizures and in animals sacrificed 5 days later this dose consistently produced extensive cellular necrosis, prominent gliosis, tissue loss and hemisphere deformity on the injected side (Fig. 1). Neuronal destruction was confluent in glutamate receptor rich regions and within or directly adjacent to the injection site: corpus striatum, dorsal hippocampus and overlying neocortex. Tissue damage was always confined to the injected hemisphere. The weight of the injected hemisphere relative to the non-injected hemisphere was reduced by an average of $28.7 \pm 1.2 \%$ in NMDA-injected saline-treated controls $(n=75)$. In these NMDA-injected controls, there was a $5 \%$ mortality rate. A similar injection of vehicle produced no signs of neurotoxicity histologically or quantitatively ( $\%$ damage $=-0.6 \pm 0.7 \%$, $n=5$ ).

MK-801, TCP, PCP and CPP all produced a dose-dependent neuroprotective effect when increasing dosages were administered i.p. 15 min after unilateral intracerebral injection of $25 \mathrm{nmol} \mathrm{NMDA}$ (Fig. 2). The degree of damage as assessed by hemisphere weight disparities (\% damage) corresponds closely to histological signs of neuronal injury (manuscript submitted for publication). MK-801 was

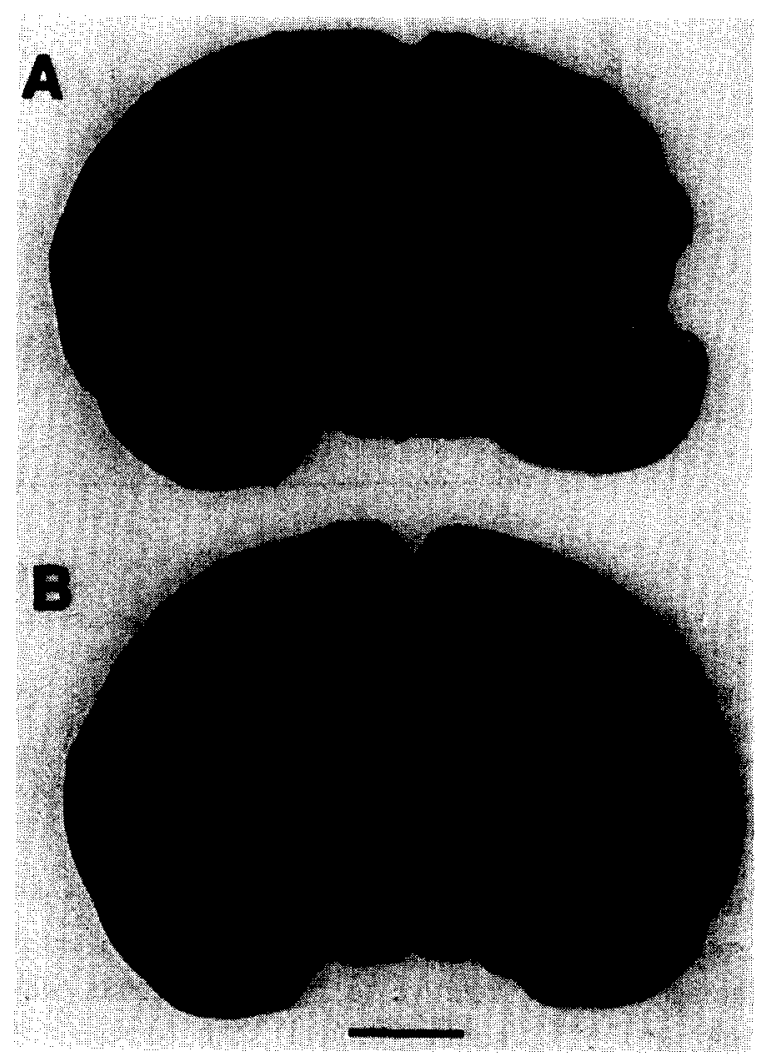

Fig. 1. Comparison of Nissl-stained coronal brain sections at the level of the dorsal hippocampus from rat pups that received i.p. injections $(0.05 \mathrm{ml})$ of either MK-801 $(0.6$ $\mu \mathrm{mol} / \mathrm{kg}(0.8 \mathrm{mg} / \mathrm{kg})$, panel B) or saline (panel A) $15 \mathrm{~min}$ after intrastriatal injection of NMDA $(25 \mathrm{nmol} / 0.5 \mu \mathrm{l})$ on day 7 . Pups were sacrificed 5 days later. Panel $A$ demonstrates the unilateral neuropathologic lesion that results from intrastriatal injection of $25 \mathrm{nmol}$ NMDA. Typically, the lesion extends into the dorsal hippocampus and overlying neocortex. In contrast, panel $\mathrm{B}$ demonstrates that there is little evidence of neuronal injury in animals post-treated with MK-801. A similar level of protection was achieved with a $47 \mu \mathrm{mol} / \mathrm{kg}$ dose of TCP. CPP and PCP when administered similarly failed to completely protect the brain histologically. In saline-treated NMDAlesioned pups there were signs of reactive gliosis near the injection tract and the striatal size was reduced in the injected hemisphere compared with the other side. Scale bar $=2 \mathrm{~mm}$. 


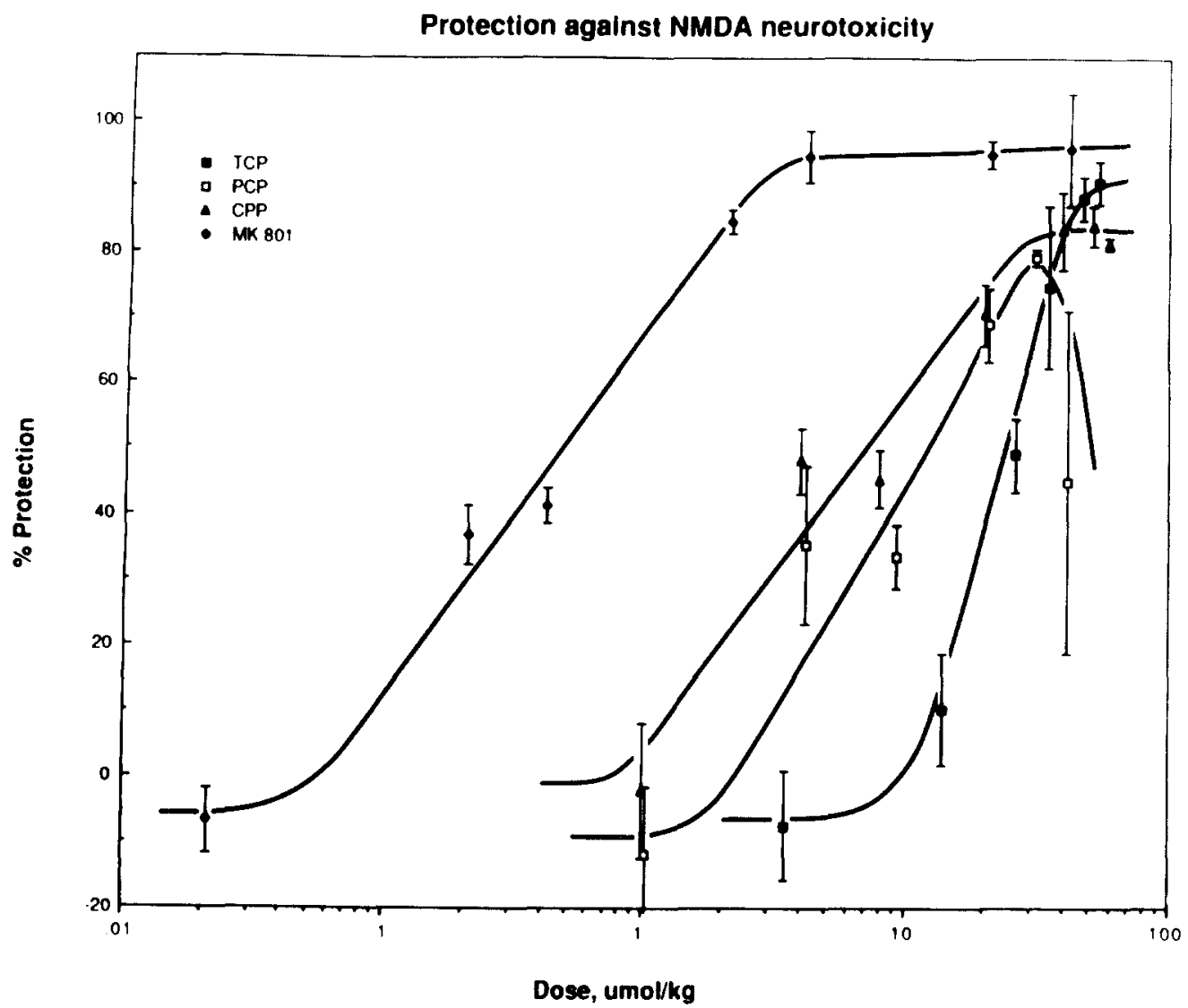

Fig. 2. Quantitative comparison of neuroprotective effects of increasing dosages of the NMDA antagonists MK-801, TCP, PCP, and CPP against NMDA-induced neuronal damage assessed by comparison of hemisphere weight disparities in brains of 12-day-old rat pups. Neuroprotective drugs were administered (i.p. injection, $0.05 \mathrm{ml}$ ) $15 \mathrm{~min}$ after intrastriatal injection of NMDA (25 nmol/0.5 $\mu 1)$ in 7-day-old rats. Pups were sacrificed 5 days later. Percent protection refers to the hemisphere weight disparities of neuroprotectant-treated pups that had received unilateral NMDA injections compared to values of saline-treated NMDA-injected controls (see Materials and Methods for details). All drugs produced a dose-dependent neuroprotective effect against NMDA neurotoxicity.

the most potent neuroprotectant tested with a $50 \%$ protective dose $\left(\mathrm{PD}_{50}\right.$ : dose required to reduce damage by $50 \%$ relative to NMDA-injected controls) of $0.625 \mu \mathrm{mol} / \mathrm{kg}$ (Table I). Nine dosages of MK-801 were tested ranging from 0.02 to 41.7 $\mu \mathrm{mol} / \mathrm{kg}$ (Fig. 2). The lowest dose that was significantly neuroprotective was $0.21 \mu \mathrm{mol} / \mathrm{kg}$ (\% protection: $37.9 \pm 4.6 \%$ MK- 801 treated, $n=8, P<$ 0.001). At this dose, however, pups still manifested behavioral signs of severe seizures. Intermediate doses that completely blocked behavioral signs of seizures were not entirely neuroprotective. Maximal and complete neuroprotection was achieved at a dose of $4.2 \mu \mathrm{mol} / \mathrm{kg}$ (equivalent to $0.8 \mathrm{mg} / \mathrm{kg}$; Fig. 1). Higher doses were equally effective, however, the highest dose tested $(41.6 \mu \mathrm{mol} / \mathrm{kg})$ produced a $70 \%$ rate of mortality compared to $5 \%$ among
NMDA-injected controls. The increase in mortality

\section{TABLE I}

\section{0\% Protective dose against NMDA neurotoxicity}

Doses of neuroprotective compounds required to achieve $50 \%$ protection $\left(\mathrm{PD}_{50}\right)$ against neuronal injury in rats injected intrastriatally with NMDA $(25 \mathrm{nmol} / 0.5 \mu \mathrm{l})$ on day 7. Neuroprotective drugs were administered i.p. $15 \mathrm{~min}$ after NMDA injection. Pups were sacrificed 5 days later and neuroprotection was assessed by comparison of cerebral hemisphere weight disparities. $95 \%$ Confidence intervals for each $\mathrm{PD}_{50}$ are indicated in parentheses.

\begin{tabular}{lrc}
\hline & $P D_{50}(\mu$ moll $/ \mathrm{kg})$ & $95 \%$ Confidence interval \\
\hline MK-801 & 0.625 & $(0.216,1.810)$ \\
CPP & 8.835 & $(3.926,19.884)$ \\
PCP & 10.847 & $(5.586,21.064)$ \\
TCP & 24.052 & $(17.067,33.895)$ \\
\hline
\end{tabular}


TABLE II

\section{Maximum protection against NMDA neurotoxicity}

Maximum level of neuroprotection achieved by NMDA antagonists and doses required. NMDA was injected unilaterally into the posterior striatum of 7-day-old rats. Neuroprotective compounds were administered i.p. 15 min later. Pups were sacrificed 5 days later and neuroprotection was assessed by comparison of hemisphere weight disparities between treated and untreated NMDA-injected pups. Values in parentheses are levels of protection achieved at doses that increased mortality rate above that for NMDA-injected controls. ${ }^{*}$ Vs MK-801, $P<$ $0.05 ;{ }^{* *}$ vs MK- $801, P<0.005 ;{ }^{+}$vs PCP, $P<0.01$.

\begin{tabular}{lcc}
\hline & Maximum protection $(\%)$ & Dose $(\mu \mathrm{mol} / \mathrm{kg})$ \\
\hline MK-801 & $94.89 \pm 3.95$ & 4.17 \\
CPP & $84.42 \pm 3.03^{*}$ & 51.38 \\
PCP & $69.05 \pm 5.57$ & 20.54 \\
& $(79.36 \pm 1.18)^{* *}$ & $(30.82)$ \\
TCP & $88.80 \pm 4.74^{+}$ & 47.05 \\
& $(91.00 \pm 3.38)$ & $(54.22)$ \\
\hline
\end{tabular}

was not the result of immediate toxicity to MK-801 but rather pups died 2-3 days after treatment. Brain size was also reduced in pups that received this dose (unpublished observation).

TCP was the least potent neuroprotective agent with a $\mathrm{PD}_{50}$ of $24.1 \mu \mathrm{mol} / \mathrm{kg}$ (38 times less potent than MK-801; see Table I). The two lowest doses tested failed to produce significant neuroprotection $(3.5 \mu \mathrm{mol} / \mathrm{kg},-7.5 \pm 8.4 \%$ protection; $14.0 \mu \mathrm{mol} / \mathrm{kg}$, $10.2 \pm 8.6 \%$ protection). The higher of the two doses $(14.0 \mu \mathrm{mol} / \mathrm{kg})$ eliminated the behavioral seizures induced by intracerebral injections of NMDA. Intermediate dosages (26.2 and $35.0 \mu \mathrm{mol} /$ $\mathrm{kg}$ ) prevented confluent neuronal necrosis, although the weight of the injected hemisphere was still reduced relative to the contralateral hemisphere. Maximal neuroprotection achieved was $91.0 \pm 3.4 \%$ protection at $54.2 \mu \mathrm{mol} / \mathrm{kg}(P<0.001)$ and was not significantly different from the maximal protection attained by MK-801 or CPP (Table II). The same dose of TCP produced respiratory depression and extended periods of apnea. As a result there was a slight increase in mortality (12\%). Similar neuroprotection resulted from a lower dose of TCP that did not increase mortality $(89.0 \pm 4.7 \%$ protection, 35.0 $\mu \mathrm{mol} / \mathrm{kg}$ dose, $P<0.001)$.

PCP was tested at doses ranging from 1 to 41 $\mu \mathrm{mol} / \mathrm{kg}$ and was $50 \%$ protective at a dose of 10.8 $\mu \mathrm{mol} / \mathrm{kg}$ (17 times less potent than MK-801, Table I). The lowest dose tested partially eliminated the behavioral signs of seizures but was not protective (1 $\mu \mathrm{mol} / \mathrm{kg},-11.9 \pm 10.5 \%$ protection). $4.1 \mu \mathrm{mol} / \mathrm{kg}$ was the lowest significantly neuroprotective dose examined $(35.1 \pm 12.1 \%$ protection, $P<0.01)$. Maximal neuroprotection achieved without increasing mortality was $69.0 \pm 5.6 \%$ protection at a $20.5 \mu \mathrm{mol} / \mathrm{kg}$ dose (Table II). A dose of $30.1 \mu \mathrm{mol} / \mathrm{kg}$ resulted in $79 \%$ protection while increasing the mortality rate to $30 \%$. The maximum neuroprotection achieved by PCP was significantly lower than that for both MK-801 and TCP (\% protection: 79.3 $\pm 1.2 \%, 30.8 \mu \mathrm{mol} / \mathrm{kg} \mathrm{PCP}, n=7$ vs $95.0 \pm 4.0 \%$, $4.2 \mu \mathrm{mol} / \mathrm{kg} \mathrm{MK}-801, n=8, P<0.005$; vs $89.8 \pm$ $4.7 \%, 47.0 \mu \mathrm{mol} / \mathrm{kg} \mathrm{TCP}, n=8, P<0.01)$ but did not differ from the maximally effective dose of CPP. The highest dose tested resulted in respiratory depression and prolonged apnea. The same dose reduced the neuroprotective effect of PCP (45 \pm $26.4 \%$ protection) and produced a $70 \%$ mortality rate.

CPP was 14 times less potent than MK-801 in protecting against NMDA-induced neuronal injury $\left(\mathrm{PD}_{50}=8.8 \mu \mathrm{mol} / \mathrm{kg}\right.$, Table I). Dosages tested up to $8 \mu \mathrm{mol} / \mathrm{kg}$ were unable to reduce the severity of NMDA-mediated behavioral seizures. The lowest dose to significantly reduce neuronal injury as assessed by hemisphere weight was $4 \mu \mathrm{mol} / \mathrm{kg}$ ( 48.2 $\pm 4.9 \%$ protection, $P<0.001$ ). A $20.0 \mu \mathrm{mol} / \mathrm{kg}$ dose of CPP completely eliminated seizure activity and prevented confluent cellular injury $(70.6 \pm 4.7 \%$ protection). The maximal level of neuroprotection achieved by CPP was significantly lower than that for MK-801 (\% protection: $84.4 \pm 3.0 \%$ CPP, 51.3 $\mu \mathrm{mol} / \mathrm{kg}, n=9$ vs $95.0 \pm 4.0 \%$ MK- $801,4.2$ $\mu \mathrm{mol} / \mathrm{kg}, n=8, P<0.05$ ) but did not differ from the maximum neuroprotection of TCP or PCP (Table II). Doses of CPP tested that were greater than the maximally effective dose increased mortality slightly (12\% mortality rate).

\section{DISCUSSION}

This study represents the first direct comparison of the neuroprotective characteristics of these NMDA antagonists in an in vivo system. The 3 non-competitive NMDA receptor antagonists, MK801, TCP, PCP, and the competitive NMDA receptor antagonist, CPP, all reduced NMDA-induced 
brain injury in a dose-dependent fashion when administered $15 \mathrm{~min}$ after a unilateral intracerebral injection of a fixed dose of NMDA $(25 \mathrm{nmol})$ in 7 -day-old rats. Based on the doses that were $50 \%$ protective, the rank order of neuroprotective potency was MK-801 > CPP $\geqslant$ PCP > TCP. MK-801 was 14 and 17 times more potent than CPP and PCP and was 38 times more potent that TCP. The potency trend observed between the non-competitive antagonists is in general agreement with other pharmacological and electrophysiological experiments with the exception that PCP was more potent than $\mathrm{TCP}^{11}$, 53.54. Pharmacological studies indicate that the affinity of TCP for the PCP receptor is 4-10-fold greater than the corresponding value for $\mathrm{PCP}^{16.50 .54}$. It is possible that differences in distribution, brain entry and duration of action between PCP and TCP may explain, in part, the results obtained. However, in the present study both compounds appeared similar with respect to their time of onset and duration of action. Behaviorally, all compounds tested reduced seizure activity within minutes of i.p. administration and these effects typically endured for $24 \mathrm{~h}$ at intermediate drug doses. Alternatively, the additional receptor interactions of $\mathrm{PCP}$ might explain the reversal in neuroprotective potencies observed between TCP and PCP in comparison to their affinities for the PCP receptor. TCP is a relatively selective ligand for the PCP receptor in contrast to PCP which also has an appreciable affinity for the haloperidolsensitive $\sigma$-opioid receptor. PCP exhibits a 10 -fold selectivity for the PCP receptor over the $\sigma$-receptor whereas TCP has a 500-1000-fold selectivity ${ }^{16,23}$.

CPP has a low micromolar affinity for the NMDA receptor and is one of the most selective and potent competitive NMDA antagonists ${ }^{10,36}$. The finding that MK-801 is more potent than CPP in antagonizing NMDA neurotoxicity is consistent with the activities of these compounds in blocking NMDAmediated depolarization of motor neurons ${ }^{3}$.

Significant differences in the maximum protection against NMDA damage were observed between these compounds. MK-801 and TCP were completely neuroprotective whereas $\mathrm{CPP}$ only achieved $84 \%$ protection. PCP was least effective $(69 \%$ protection). MK-801 achieved complete protection at a dose 10 -fold lower than the doses required by the other antagonists to achieve their maximal neuroprotection. The effectiveness of CPP and PCP were limited due to the increase in mortality observed at doses required to achieve near complete protection.

All compounds tested produced muscle relaxation, sedation and reduced the behavioral signs of seizures $^{7,26,49}$. At the highest doses tested, each compound depressed respiratory function and resulted in prolonged periods of apnea leading to an increase in mortality relative to NMDA-injected controls. Using the ratio of the dose that produced $50 \%$ protection relative to the dose that began to produce an increase in mortality, MK- 801 had the most favorable therapeutic window, PCP and TCP the worst, and CPP was intermediate. There was a 70-fold dose range over which MK-801 was over $50 \%$ neuroprotective whereas similar dose ranges for CPP, PCP, and TCP were 7-, 3-, and 2-fold respectively.

These results are in agreement with other in vivo reports indicating that $\mathrm{MK}-801$ can attenuate NMDA-induced brain damage although the present study provides the first comparison to other NMDA antagonists ${ }^{13,14,33,34}$. However, in adult rats, a much larger $(10 \mathrm{mg} / \mathrm{kg}$ i.p.) pretreatment dose of MK-801 was required to completely prevent neuronal degeneration in the hippocampus caused by direct intracranial injection of $20 \mathrm{nmol} \mathrm{NMDA}^{13}$. In the present study, $1 \mathrm{mg} / \mathrm{kg}$ MK-801 given $15 \mathrm{~min}$ after intrastriatal injection of NMDA completely prevented NMDA-induced damage as assessed both histologically and quantitatively by comparing hemisphere weight disparities. NMDA antagonists may be more effective in immature animals compared to adults ${ }^{48}$. Developmental alterations in the pharmacokinetics of MK-801 may account, in part, for the obtained results. MK- 801 is 5 times more potent than PCP in preventing NMDA-induced neurotoxicity in in vitro chick retinal cultures ${ }^{40}$. This is in contrast to the findings in the present study in which MK-801 was 17 times more potent than PCP in preventing NMDA neurotoxicity. However, inference from in vitro studies to effects in in vivo studies is difficult. Several other reports have shown that a wide variety of NMDA antagonists can prevent in vitro NMDA and glutamate-mediated neurotoxicity in cortical neuronal cultures 5,6 .

Our results demonstrate the sensitivity of this 
system for distinguishing in vivo pharmacological potencies and efficacies of closely related glutamate antagonist compounds.

NMDA receptor antagonists are also effective in attenuating hypoxic-ischemic neuronal injury. MK801 can reduce the histological and neurological signs of hypoxic-ischemic neuronal injury in vivo in a variety of different animal models of cerebral hypoxia-ischemia ${ }^{17,22,34}$. A preliminary report suggests that MK-801 is more effective than PCP in protecting against histological signs of ischemic neuronal degeneration in the gerbil hippocampus ${ }^{25}$. In a similar model evidence indicates that CPP is also effective in preventing ischemic neuronal damage ${ }^{1}$. In addition, NMDA antagonists attenuate anoxic neuronal injury in vitro in neocortical cultures ${ }^{5}$.

Similarities between NMDA-mediated and hypoxia-ischemia-mediated neuronal injury suggest that

\section{REFERENCES}

1 Boast, C.A., Gerhardt, S.C., Pastor, G., Lehmann, J., Etienne, P.E. and Liebman, J.M., The $N$-methylD-aspartate antagonist CGS19755 and CPP reduce ischemic brain damage in gerbils, Brain Research, 442 (1988) 345-348.

2 Bristow, D.R., Bowery, N.G. and Woodruff, G.N., Light microscopic autoradiographic localization of $\left[{ }^{3} \mathrm{H}\right]$ glycine and $\left[{ }^{3} \mathrm{H}\right]$ strychnine binding sites in rat brain, Eur. $J$. Pharmacol., 126 (1986) 303-307.

3 Childs, A.M., Evans, R.H. and Watkins, J.C., The pharmacological selectivity of three NMDA antagonists, Eur. J. Pharmacol., 145 (1988) 81-86.

4 Choi, D.W., Ionic dependence of glutamate neurotoxicity, J. Neurosci., 7 (1987) 369-379.

5 Choi, D.W., Koh, J.Y. and Peters, S., Pharmacology of glutamate neurotoxicity in cortical cell culture: attenuation by NMDA antagonists, J. Neurosci., 8 (1988) 185-196.

6 Choi, D.W., Peters, S. and Viseskul, V., Dextrorphan and levorphanol selectively block $N$-methyl-D-aspartate receptor-mediated neurotoxicity on cortical neurons, $J$. Pharm. Exp. Ther., 242 (1987) 713-720.

7 Clineschmidt, B.V., Martin, G.E. and Bunting, P.R., Anticonvulsant activity of MK-801, a substance with potent anticonvulsant, central sympathomimetic and apparent anxiolytic properties, Drug Dev. Res., 2 (1982) 123-134.

8 Collins, R.C. and Olney, J.W., Focal cortical seizures cause distant thalamic lesions, Science, 218 (1982) 177-179.

9 Cotman, C.W., Monaghan, D.T., Ottersen, O.P. and Storm-Mathisen, J., Anatomical organization of excitatory amino acid receptors and their pathways, Trends Neurosci., 10 (1987) 273-280.

10 Davies, J., Evans, R.H., Herrling, P.L., Jones, A.W., Olverman, H.J., Pook, P. and Watkins, J.C., CPP, a new potent and selective NMDA antagonist. Depression of central neuron responses, affinity for $\left[{ }^{3} \mathrm{H}\right]$-AP5 binding sites on brain membranes and anticonvulsant activity, compounds with neuroprotective activity in this preparation may also be active against hypoxicischemic neuronal injury. If this hypothesis is validated, the NMDA neonatal model may provide several advantages compared with more variable hypoxia-ischemia systems.

\section{ACKNOWLEDGEMENTS}

Supported by USPHS Grants 1P01NS19613 (M.V.J.), MSTP Grant 5 T32 6M07863-07 (J.W.M.), 1K08NS01171 (F.S.S.), Grant R-326 from the United Cerebral Palsy Research and Education (M.V.J.) and a grant from the Epilepsy Foundation of America (F.S.S.). MK-801 was a gift of Dr. P. Anderson, Merck, Sharp and Dohme, West Point, PA. TCP and PCP were a gift of Dr. E. Domino at the University of Michigan.

Brain Research, 382 (1986) 169-173.

11 Fagg, G.E., Phencyclidine and related drugs bind to the activated $N$-methyl-D-aspartate receptor-channel complex in rat brain membranes, Neurosci. Lett., 76 (1987) 221227.

12 Flatman, J.A., Schwindt, P.C., Crill, W.E. and Afstrom, S.T., Multiple actions of $N$-methyl-D-aspartate on cat neocortical neurons in vitro, Brain Research, 226 (1983) 169-173

13 Foster, A.C., Gill, R., Kemp, J.A. and Woodruff, G.N., Systemic administration of MK-801 prevents $N$-methyl$\mathrm{D}$-aspartate induced neuronal degeneration in rat brain, Neurosci. Lett., 76 (1987) 307-311.

14 Gill, R., Foster, C. and Woodruff, G.N., Systemic administration of $\mathrm{MK}-801$ protects against ischemia-induced hippocampal neurodegeneration in the gerbil, J. Neurosci., 7 (1987) 3343-3349.

15 Greenamyre, J.T., The role of glutamate in neurotransmission and in neurologic disease, Arch. Neurol., 43 (1986) 1058-1063.

16 Gundlach, A.L., Largent, B.L. and Snyder, S.H., Phencyclidine and sigma opiate receptors in brain; biochemical and autoradiographical differentiation, Eur. J. Pharmacol., 113 (1985) 465-466.

17 Iversen, L.L., Woodruff, G.N., Kemp, J.A., Foster, A.C., Gill, R. and Wong, E.H.F., Pharmacology and neuroprotective effects of the NMDA antagonist MK-801. In E.G. Domino and J.M. Kamenka (Eds.), Sigma and PCP-like Compounds as Molecular Probes in Biology, NPP Press, Ann Arbor, 1988, pp. 757-766.

18 Jarvis, M.F., Murphy, D.E. and Williams, M., Quantitative autoradiographic localization of NMDA receptors in rat brain using $\left[{ }^{3} \mathrm{H}\right] \mathrm{TCP}$ binding sites, Eur. J. Pharmacol., 141 (1987) 149-152.

19 Javitt, D.C., Jotkowitz, A., Sircar, R. and Zukin, S.R., Non-competitive regulation of phencyclidine/sigma receptors by the $N$-methyl-D-aspartate receptor antagonist D(-)-2-amino-5-phosphonovaleric acid, Neurosci. Lett., 78 
(1987) 193-198.

20 Johnson, J.W. and Ascher, P., Glycine potentiates the NMDA response in cultured mouse brain neurons, Nature (Lond.), 325 (1987) 529-531

21 Kemp, J.A., Foster, A.C. and Wong, E.H.F., Noncompetitive antagonists of excitatory amino acid receptors, Trends Neurosci., 10 (1987) 294-299.

22 Kochhar, A., Zivin, J.A., Lyden, P.D. and Mazzarell, V., Glutamate antagonist-therapy reduces neurologic deficits produced by focal central nervous system ischemia, Arch. Neurol., 45 (1988) 148-153.

23 Largent, B.L., Gundlach, A.L. and Snyder, S.H., Pharmacological and autoradiographical discriminations of sigma and phencyclidine receptor binding sites in brain with (+) $-\left[{ }^{3} \mathrm{H}\right] \mathrm{SKF} 10,047,(+)-\left[{ }^{3} \mathrm{H}\right] 3-\mathrm{PPP}$ and $\left[{ }^{3} \mathrm{H}\right] \mathrm{TCP}, J$. Pharmacol. Exp. Ther., 238 (1986) 739-748.

24 Labuyere, J., Fuller, T.A., Olney, J.W., Price, M.T., Zorumski, C. and Clifford, D., Phencyclidine and ketamine protect against kainic acid-induced seizure related damage, Soc. Neurosci. Abstr., 12 (1986) 344.

25 Lawrence, J.J., Fuller, T.A. and Olney, J.W., MK-801 and PCP protect against ischemic neuronal degeneration in the gerbil hippocampus, Soc. Neurosci. Abstr., 13 (1987) 1079.

26 Leccese, A.P., Marquis, K.L., Mattia, A. and Moreton, J.E., The convulsant and anticonvulsant effects of phencyclidine (PCP) and PCP analogues in the rat, Behav. Brain Res., 19 (1986) 163-169.

27 Litchfield, J.T. and Wilcoxon, F., A simplified method of evaluating dose-effect experiments, J. Pharmacol. Exp. Ther., 96 (1949) 99-113.

28 MacDermott, A.B., Mayer, M.L., Westbrook, G.L., Smith, S.J. and Barker, J.L., NMDA-receptor activation increases cytoplasmic calcium concentration in cultured spinal cord neurons, Nature (Lond.), 321 (1986) 519-522.

29 MacDonald, J.F., Porietis, A.V. and Wojtowicz, J.M., L-Aspartic acid induces a region of negative slope conductance in the current voltage relationship of cultured spinal cord neurons, Brain Research, 237 (1982) 248-253.

30 Maragos, W.F., Chu, D.C.M., Greenamyre, J.T., Penney, J.B. and Young, A.B., High correlation between the localization of $\left[{ }^{3} \mathrm{H}\right] \mathrm{TCP}$ binding and NMDA receptors, Eur. J. Pharmacol., 123 (1986) 173-174.

31 Martin, D. and Lodge, D., Ketamine acts as a noncompetitive $N$-methyl-D-aspartate antagonist on frog spinal cord in vitro, Neuropharmacology, 24 (1985) 999-1003.

32 Mayer, M.L., Westbrook, G.L. and Guthrie, P.B., Voltage-dependent block by $\mathrm{Mg}^{2+}$ of NMDA responses in spinal cord neurons, Nature (Lond.), 309 (1984) 261-263.

33 McDonald, J.W., Silverstein, F.S., Carodona, D., Uckele, J., Chen, R. and Johnston, M.V., Neuroprotective effects of MK-801 and other compounds on perinatal hypoxicischemic injury. In E.F. Domino and J.-M. Kamenka (Eds.), Sigma and PCP like Compounds as Molecular Probes in Biology, NPP Press, Ann Arbor, MI, 1988, pp. 697-707.

34 McDonald, J.W., Silverstein, F.S. and Johnston, M.V., MK-801 protects the neonatal brain from hypoxic-ischemic damage, Eur. J. Pharmacol., 140 (1987) 359-361.

35 McDonald, J.W., Silverstein, F.S. and Johnston, M.V., Neurotoxicity of $N$-methyl-D-aspartate is markedly enhanced in developing rat central nervous system, Brain Research, in press.

36 Murphy, D.E., Schneider, J., Boehm, C., Lehmann, J. and Williams, M., Binding of $\left[{ }^{3} \mathrm{H}\right]$ 3-(2-carboxypiperazin4-yl) propyl-1-phosphonic acid to rat brain membranes: a selective high affinity ligand for $N$-methyl-D-aspartate receptors, J. Pharmacol. Exp. Ther., 240 (1987) 778-784 37 Nadler, J.V., Perry, B.W. and Cotman, C.W., Intraventricular kainic acid preferentially destroys hippocampal pyramidal cells, Nature (Lond.), 271 (1978) 676-677.

38 Nowak, L., Bregestovski, P., Ascher, P., Herbet, A. and Prochiantz, A., Magnesium gates glutamate-activated channels in mouse central neurons, Nature (Lond.), 307 (1984) $462-465$.

39 Olney, J.W., Ho, O.L. and Rhee, V., Cytotoxic effects of acid and sulfate containing amino acids on the infant mouse central nervous system, Exp. Brain Res., 14 (1971) 61-76.

40 Olney, J., Price, M., Salles, K.S., Labruyere, J. and Frierdich, G., MK-801 powerfully protects against $N$ methyl-D-aspartate toxicity, Eur. J. Pharmacol., 141 (1987) $357-361$

41 Reynolds, I.J., Murphy, S.N. and Miller, R.J., 3H-labelled MK-801 binding to the excitatory amino acid receptor complex from rat brain is enhanced by glycine, Proc. Natl. Acad. Sci. U.S.A., 84 (1987) 7744-7748.

42 Robinson, M.B. and Coyle, J.T., Glutamate and related acidic excitatory neurotransmitters from basic science to clinical applications, FASEB J., 1 (1987) 446-455.

43 Rothman, S., Synaptic release of excitatory amino acid neurotransmitter mediates anoxic neuronal death, $J$. Neurosci., 4 (1984) 1884-1891.

44 Rothman, S. and Olney, J., Glutamate and the pathophysiology of hypoxic-ischemic brain damage, Ann. Neurol., 19 (1986) 105-111.

45 Rothman, S.M. and Olney, J.W., Excitotoxicity and the NMDA receptor, Trends Neurosci, 10 (1987) 299-301

46 Simon, R.P., Swan, J.H., Griffiths, T. and Meldrum, B.S. Blockade of $N$-methyl-D-aspartate receptors may protect against ischemic damage in the brain, Science, 226 (1984) 850-852.

47 Sloviter, R.S., 'Epileptic' brain damage in rats induced by sustained electrical stimulation of the perforant path. I. Acute electrophysiological and light microscopic studies, Brain Res. Bull., 10 (1983) 675-697.

48 Tsumoto, T. Hagihard, K., Sato, H. and Hata, Y., NMDA receptors in the visual cortex of young kittens are more effective than those of adult cats, Nature (Lond.), 327 (1987) 513-514.

49 Turski, L., Klockgether, T., Sontag, K.H., Herrling, P.L. and Watkins, J.C., Muscle relaxant and anticonvulsant activity of CPP, a novel $N$-methyl-D-aspartate antagonist, in rodents, Neurosci. Lett., 73 (1987) 143-148.

50 Vincent, J.P., Kartalouski, B., Geneske, P., Kamenka, J.M. and Lazdunski, M., Interaction of phencyclidine ('angel dust') with a specific receptor in rat brain membranes, Proc. Natl. Acad. Sci., U.S.A., 76 (1979) 46784682.

51 Weiss, J., Goldberg, M.P. and Choi, D.W., Ketamine protects cultured neocortical neurons from hypoxic injury, Brain Research, 380 (1986) 186-190.

52 Wieloch, T., Hypoglycemia-induced neuronal damage prevented by and $N$-methyl-D-aspartate antagonist, Science, 230 (1985) 681-683.

53 Wong, E.H.F., Kemp, J.A. Priestly, T., Knight, A.R., Woodruff, G.N. and Iversen, L.L., The anticonvulsant MK-801 is a potent $N$-methyl-D-aspartate antagonist, Proc. Natl. Acad. Sci. U.S.A., 83 (1986) 7104-7108.

54 Wong, E.H.F., Knight, A.R. and Woodruff, G.N., $\left[{ }^{3} \mathrm{H}\right] \mathrm{MK}-801$ labels a site on the $N$-methyl-D-aspartate receptor channel complex in rat brain membranes, $J$. Neurochem., 50 (1988) 274-281. 